\title{
The Potency of Endofit Fungi in Cocoa as Biological Agent to Control Cocoa Pod Disease Caused by Phytophthota Palmivora (Butler) Butler
}

\author{
I Made Sudarma*, Ni Made Puspawati, and I Ketut Suada \\ Study program of Agroecotechnology, Faculty of Agriculture, Udayana University \\ Jl. PB. Sudirman, Denpasar, Bali \\ *Corresponding author: sudarma_made@ymail.com
}

\begin{abstract}
Cocoa pod disease caused by the fungus Phytophthora palmivora has resulted in loss of cacao in Indonesia, especially in Bali. So far the disease control strategy is not fully understood. So there is a need to find an alternative by using endophytic fungi associated with cocoa plant. Endophytic fungi are needed to be explored in all parts of the cocoa plant such as stems, leaves and husks. The prevalence of fungal endophyte was determined by the size of its domination on the surface tissue for protection against pathogen. The exploration of the endophytic fungi benefits is aimed at finding biological agents that could control of pathogenic P. palmivora. The results showed that 15 types of endophyte fungi have been found in the healthy leaves, stem and pod husks, with the prevalence of fungal endophyte originated from healthy leaf Mecelia sterilia (hyphae sterile) around 30\%, the endophyte fungi originated from the healthy cocoa stem are Mycelia sterilia, Neurospora spp and Trichoderma spp around 25\%. While the endophytic fungi originated from healthy skin fruit is Trichoderma spp. around $35 \%$. The in vitro test results of endophytic fungi antagonistic against $P$. palmivora indicated that the endophyte fungi originated from the leaf namely Aspergillus spp was obtained at $80 \pm 2 \%$, A. niger $90 \pm 2 \%$, A. flavus $100 \%$, and Trichoderma spp. $90 \pm 1.5 \%$, the endophytic fungus originated from rods namely Neurospora spp. was $95 \pm 2 \%$, and Trichoderma spp. was $90 \pm 2 \%$. While the endophytic originated from rind namely Neurospora spp . was $95 \pm 1.5 \%$ and Trichoderma spp. was $80 \pm 2 \%$. The results of in vivo test of antagonistic endophytic fungi against $P$. palmivora showed that all of endophytic fungi (Aspergillus sp., A. niger, A. flavus, Neurospora sp., and Trichoderma sp.) have a significant effect in suppressing the growth of mycelium P. palmivora.
\end{abstract}

Keywords: Endophytic Fungus, Phytophthora Palmivora, Inhibition, Prevalence, Biological Agents

\section{INTRODUCTION}

Pod rot is important disease in cocoa cultivation in Indonesia recently, and also in some cocoa producer countries [1]. This disease has average about $20-30 \%$ per year on damaging cocoa plant all over the world. In some cases as happen in Samoa America, the cocoa did not planted commercially because of this disease [2]. Cocoa was planted around 532.000 ha in Indonesia on the year of 1999. More than 70\% cocoa farmers are the farmer in Indonesia. Indonesia is the top third cocoa exporting countries in the world, produce around 335.000 ton per year, with value 294 million US dollars [3].

Indonesia is the biggest archipelago in the world with has 17.000 islands (6000 has inhabitant). Indonesia is tropical country with various climate and humidity from highland to the lowland. Most of the areas are lowland, while the biggest island has a mountain. Tropical climate with rainy season and high humidity in many areas, some Phytophthora diseases caused a significant damage and uncontrollable. Phytophthora spp. causes disease on the agricultural plants, horticultural and industrial in Indonesia. At least 11 species Phytophthora has been reported as they resulted in economically yield loss in Indonesia. Phytophthora palmivora has been identified to cause an important disease from economical point of view compared to other Phytophthora species in Indonesia. Phytophthora palmivora infected more than 138 plants species, with caused average loss around 25$50 \%$ on cocoa plant, while P. capsici caused $52 \%$ of decreasing yield on pepper plant. This disease infected many plants but the demage still not be able to be counted, direct demage through fruit infection is showed by the black rotten. Recently, a set of fruits from young fruit to mature one is very sensitive to the infection. [3].

Endophyitic fungi which have been isolated from the tissue of healthy give an new hope for biocontrol of cocoa pod disease. The study from Mejia et al. (2008) showed that $40 \%(21 / 52)$ of isolated endophytic fungi were able to control $P$. palmivora [4]. One of the isolated fungi which has antagonist characteristic through a simple competition mechanism is Trichoderma sp.

\section{RESEARCH METHOD}

\section{Endophyte Isolation}

Endophytic fungi used in this study were collected from cocoa planted in Tabanan. The survey of cocoa leaf and fruit was done in four different locations at cocoa plantation centre in Tabanan regency. The obtained leaf and fruit were washed by flowing water with following 
methods: 32 peaces of leaf with size $4 \mathrm{~mm}^{2}$, the shoot and the flower were cut from the middle of each, the surface was sterilized in $0,525 \%$ sodium hypochlorite for 3 minute, and $70 \%$ ethanol for 2 minute; and washed by sterile water for 1 minute; and then put in the PDA media (containing antibiotic livoploxacyne $0,1 \%$ (w/v). The grown fungi from the piece of leaf were transferred to the tube containing PDA for storage and classified through morphospecies. In order to isolate the endophyte from rod and fruit, those parts were washed by flowing water and then devided into 8 pieces. Fruit were cut into 16 cubical form $\left(8 \mathrm{~mm}^{3}\right), 8$ from exocarp and 8 from mesocarp. The surfaces were sterilized and storage with similar procedure as isolation from the leaf.

\section{Identification of Endophytic Fungi}

The storage endophytic fungi were grown on petri disc containing PDA and repeated 5 times. The cultures were incubated at dark room and temperature $\pm 27^{\circ} \mathrm{C}$. The isolate was identified macroscopically after 3 days of culture periode by observe of the colony colour, growth rate, and microscopically identification was done to investigate septa on the hyphae, the spora form/conidia and the sporangiophore. Fungi identification was done by using some reference books of Samson et al., 1981; Pitt and Hocking, 1997; Barnett and Hunter, 1998; Indrawati et al., 1999 [5][6][7][8].

\section{Prevalence of Endophytic Fungi}

Determination of endopyhtic fungi prevalence were done based on frequency of endophytic fungi isolate were found (eight pieces from leaf, rod, flower and fruit) per petri disc, divided by all founded isolates timed by $100 \%$. The number of isolate prevalence will be determining the dominancy of the endophytic fungi on the healthy cocoa plant.

\section{Inhibition Assay of Endophytic Fungi to the Pathogen}

The ability of each endophytic fungi to inhibit the growth of pathogenic $P$. palmivora was tested by dual culture technique (one pathogen colony in the middle and two endophytic fungi next to the pathogen, side by side). Their inhibition can be calculated as follow [9][10]:

$$
\text { Inhibitory }(\%)=\frac{\mathrm{A}-\mathrm{B}}{\mathrm{A}} \times 100
$$

$\mathrm{A}=$ colony diameter $P$. palmivora in the single culture $(\mathrm{mm})$

$\mathrm{B}=$ colony diameter $P$. palmivora in the dual culture (mm).

\section{In Vivo Antagonistic Assay}

In vivo antagonistic assay of endophytic fungi was done by impaling the fresh fruit by small spleden needle for 20 times, and then covered by the spore of antagonist fungi (spore from one petri dish was dissolved in $250 \mathrm{ml}$ sterile aquadest), then dyed into the spore of pathogenic fungi ( $P$. palmivora). The assays were setting as follows: $\mathrm{A}=$ control (without covering by antagonist)

$\mathrm{B}=$ Antagonist treatment 1 (spore suspension $5 \times 10^{7}$ )

$\mathrm{C}=$ Antagonist treatment 2 (spore suspension $5 \times 10^{7}$ )

$\mathrm{D}=$ Antagonist treatment 3 (spore suspension $5 \times 10^{7}$ )
$\mathrm{E}=$ Antagonist treatment $4\left(\right.$ spore suspension $\left.5 \times 10^{7}\right)$

$\mathrm{F}=$ Antagonist treatment $5\left(\right.$ spore suspension $\left.5 \times 10^{7}\right)$

All of the treatment was repeated 5 times. Experiment was designed by random group design, and after variance analysis by ANOVA following by signi-ficance test at level of $5 \%$. The infection parameters were measured by counting the number of infected impale divide by all impale (20 times) timed by $100 \%$.

\section{RESULTS AND ANALYSIS}

\section{Endophytic Fungi}

The results showed that endophytic fungi obtained from cocoa plant namely the endophyte from leaf were 7 isolates of Micelia sterilia with, 2 isolates of Aspergillus spp., 3 isolates of Aspergillus niger, 1 isolate of Aspergillus flavus, 1 isolate of Fusarium sp., 1 isolate of Mucor sp., 5 isolates of Trichoderma spp. and 1 isolate of Verticillium sp. Endophyte from the rod were 5 isolates of Micelia sterilia, 1 isolate of Botryoderma sp. 1 isolate of Dactylium sp. 2 isolates of Fusarium sp., 1 isolate of Oidium sp. 5 isolates of Neurospora spp. and 5 isolates of Trichoderma spp. The endophyte obtained from the skin fruit were 3 isolates of Micelia sterilia, 1 isolate of Cylindrocarpon sp., 2 isolates of Fusarium sp. 1 isolate of Mortierella sp. 5 isolates of Neuro-spora spp., 1 isolate of Septocylindrium sp. and 7 isolates of Trichoderma spp. as showed in Table 1 and Fig. 1.

Endophytic fungi normally exist without any symptoms (asymptomatically) in the tissue of the host plant and they have strong attachment to their host. There are two main reasons of thus attachment i.e. first, they are growing indicated that endophyte is able to found in all kind of plant with high abundance and vary. Most of this endophyte are found in internal infection site at leaf, root, rod and skin then transmitted horizontally through the spore. Secondly, the endophyte can produce mycotoxin and convert the physiology and morphology of the host plant. Mycotoxin from endophyte has an advantage to the host plant as acquired plant defenses to face herbivore insect and grass host [11].

Endophyte from leaf and rod of Endofit yang berasal dari daun dan Hevea brasiliensis which frequent to found are the genus of Penicillium, Pestalotiopsis and Trichoderma [12]. Aspergillus and Fusarium produced bioactive compound from the host which contain insecticide activity, cytotoxic and anticancer [13]. The study from Amin et al. (2014) have found 6 genus of endophytic fungi in VSD M.05 resistant cocoa plant, namely Curvularia sp., Fusarium sp., Geotrichum sp., Aspergillus sp., Gliocladium sp., and Colletotrichum sp., and another four were not be able to identified [14].

\section{Prevalence of Endophytic Fungi}

This study showed that prevalence of endophytic fungi originated from healthy leaf is Mycelia sterilia (sterile hypha) around $30 \%$, in endophyte from healthy cocoa rod are Mycelia sterilia, Neurospora spp. Trichoderma spp. around $25 \%$ of each. While in the endophyte from the fruit skin is Trichoderma spp. 35\% 
(Table 1). Trichoderma spp., are the dominant genus in south part of China (4 isolates, 23,5\%). It has been reported that endophytic fungi can produce antitumor or antifungi activity. The fungi which has been isolated from the skin fruit of medicinal plant including Pasecilomyces sp., Cephalosporium sp., Mortierella sp., Mucor sp., Trichoderma sp., and Cladosporium sp. [15].

TABLE 1.

THE ENDOPHYTIC FUNGI PREVALENCE ON THE LEAF, ROD AND FRUIT OF THE HEALTHY COCOA PLANT.

\begin{tabular}{lccc}
\hline \multicolumn{1}{c}{ Fungi } & Endophyte from the leaf & Endophyte from the rod & Endophyte from the fruit skin \\
\hline Micelia sterilia & $6(30 \%)^{*}$ & $5(25 \%)$ & $3(15 \%)$ \\
Aspergillus spp. & $2(10 \%)$ & - & - \\
Aspergillus niger & $3(15 \%)$ & - & - \\
Aspergillus flavus & $1(5 \%)$ & - & \\
Botryoderma sp. & - & $-5 \%)$ & $1(5 \%)$ \\
Cylindrocarpon sp. & - & $1(5 \%)$ & $2(10 \%)$ \\
Dactylium sp. & $1(5 \%)$ & $2(10 \%)$ & $1(5 \%)$ \\
Fusarium sp. & - & $1(5 \%)$ & - \\
$\begin{array}{l}\text { Odium } \text { sp. } \\
\text { Mortierella } \text { sp. }\end{array}$ & $1(5 \%)$ & - & $5(25 \%)$ \\
Mucor sp. & - & - & $1(5)$ \\
Neurospora spp & $5(25 \%)$ & $5(25 \%)$ & $7(35 \%)$ \\
Septocylindrium & $1(5 \%)$ & $5(25 \%)$ & - \\
Trichoderma spp. & 20 & - & 20 \\
Verticillium $\mathrm{sp}$ & & 20 & \\
\hline Total & & & \\
\hline
\end{tabular}

*Note: the percentage is prevalence (frequency of isolates)

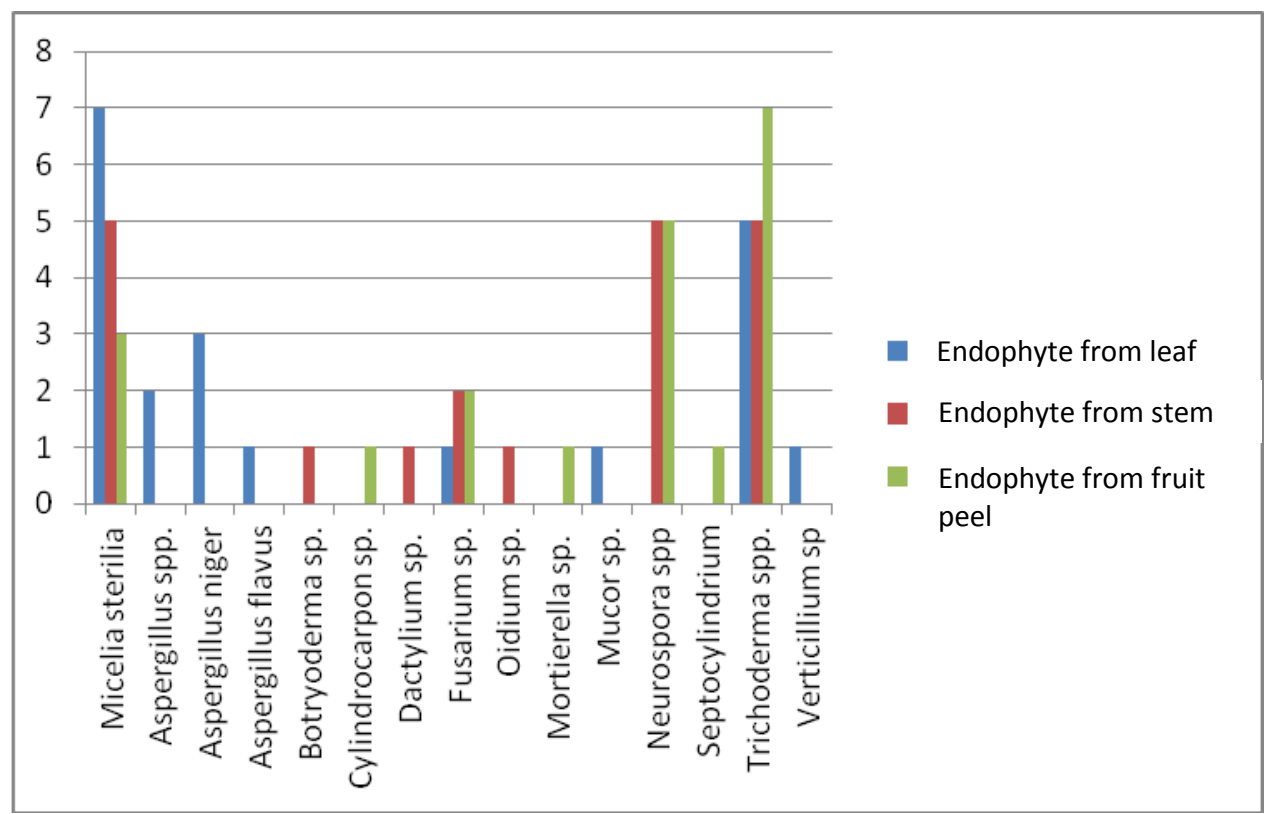

Fig. 1. Endophytic fungi originated from leaf, rod and fruit skin of cocoa plant. 
The Results of Antagonistic Assay Endo-phytic Fungi on Phytophthota palmivora

The result of this study showed that its obtained around $80 \pm 2 \%$ of Aspergilus spp., $90 \pm 2 \%$ of A. niger, $100 \%$ of $A$. flavus and $90 \pm 1,5 \%$ of Trichoderma spp in endophyte from leaf. $95 \pm 2 \%$ of Neurospora spp. and $90 \pm 2 \%$ of Trichoderma spp. are obtained from endophyte which originated from rod. While $95 \pm 1,5 \%$ of Neurospora spp. and $80 \pm 2 \%$ of Trichoderma spp. from endophyte originated from the fruit skin (Table 2, Fig. 2).
Aspergillus flavus and A. terreus which growing internally are seed transmitted fungi that can inhibit the growth of pathogenic Rhizoctonia solani Khun, and then it's useful for the control of seed transmitted diseases which infected several important plant [16]. Most endophyte which is found in cocoa rod are the genus that familiar known as soil fungi (Clonostachys and Trichoderma) [4].

TABLE 2.

INHIBITORY ASSAY OF ENDOPHYTIC FUNGI TO P. PALMIVORA

\begin{tabular}{lccc}
\hline \multicolumn{1}{c}{ Fungi } & Endophyte from leaf & Endophyte from rod & Endophyte from fruit skin \\
\hline Micelia sterilia & - & - & - \\
Aspergillus spp. & $80 \pm 2 \%$ & - & - \\
Aspergillus niger & $90 \pm 2 \%$ & - & - \\
Aspergillus flavus & $100 \%$ & - & - \\
Botryoderma sp. & - & - & - \\
Cylindrocarpon sp. & - & - & - \\
Dactylium sp. & - & - & - \\
Fusarium sp. & - & - & - \\
Oidium sp. & - & - & - \\
Mortierella sp. & - & - & - \\
Mucor sp. & - & - & - \\
Neurospora spp & - & $95 \pm 2 \%$ & $95 \pm 1,5 \%$ \\
Septocylindrium & - & - & - \\
Trichoderma spp. & $90 \pm 1,5 \%$ & $90 \pm 2 \%$ & $80 \pm 2 \%$ \\
Verticillium $s p$ & - & - & - \\
\hline
\end{tabular}
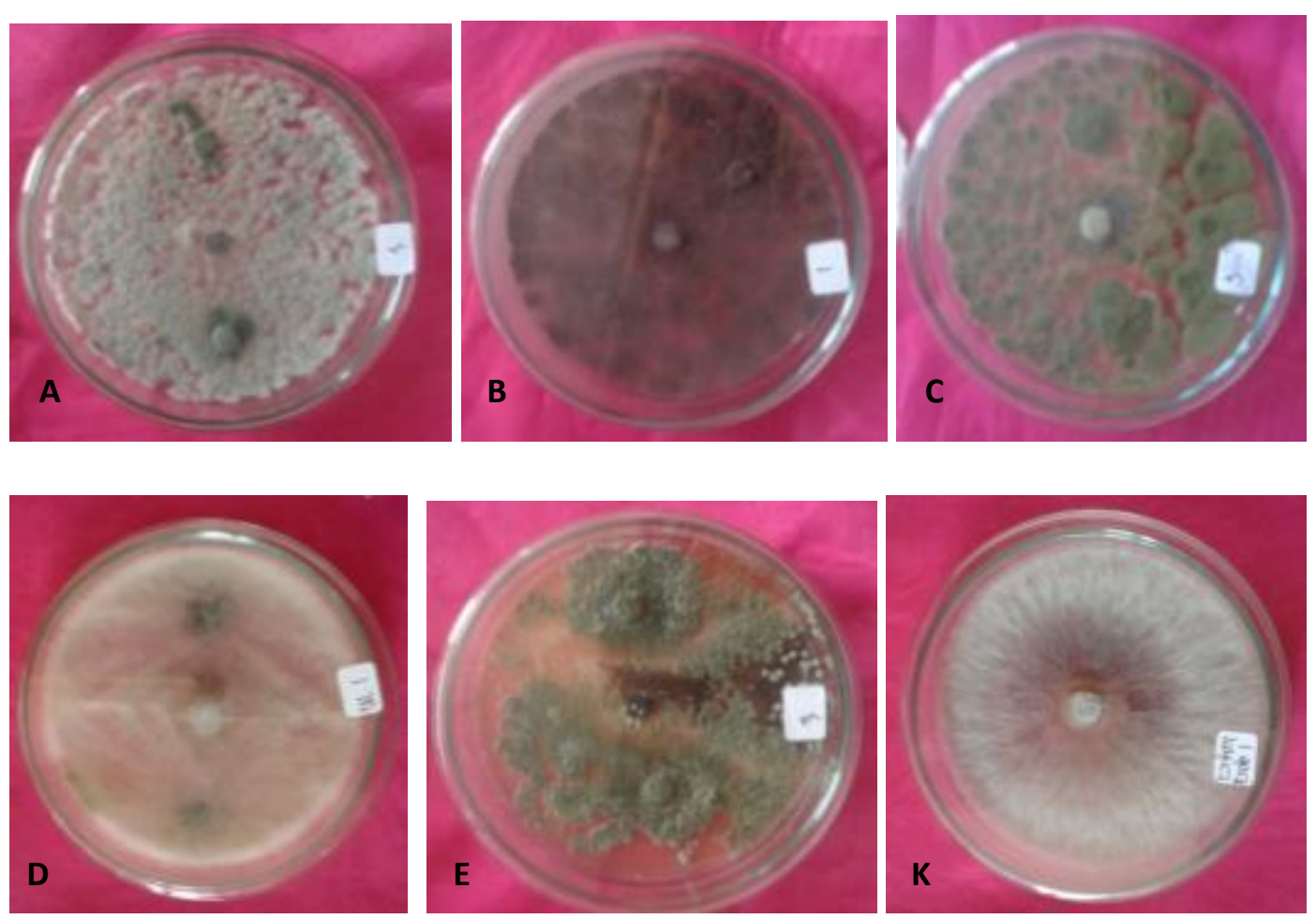

Fig. 2. Antagonistic assay of endophytic fungi to P. palmivora, (A) Aspergillus sp., (B) Aspergillus niger, (C) Aspergillus flavus, (D) Neurospora sp., (E) Trichoderma sp., and (K) Control (Phytophthora palmivora)

7 day after incubation

Trichoderma sp. also found as endophtic fungus which is able to inhibit Crinipellis perniciosa (Stahel) Singer, the main cause of Witches Broom disease on cocoa plant [17]. Trichoderma, has potency as a biological agent to control Phytophthora spp., moreover 
Fusarium and Verticillium are antagonistic to some pathogenic fungi [18].

\section{In Vivo Antagonistic Assay}

The in vivo antagonistic assay showed that all five biological agents have a significant different on inhibition of the $P$. palmivora growth. The five biological agents that tested on the fresh fruit i.e. Aspergillus sp., A. niger, A. flavus, Neurosporas sp., Trichoderma sp. (Fig. 3).
Among endophytic fungi founded on Hevea brasiliensis, Trichoderma is the most often been found and isolated [12], and is able to inhibit the growth of $P$. palmivora either by competition or antibiosis mechanism. The percentage of infection are significantly different in all treatment compared to the control (Fig. 3, Table 3). Antagonistic treatment using Aspergillus sp. has percentage infection around $10 \%$, while the other ( $A$. niger, A. flavus, Neurospora sp. and Trichoderma sp.) has percentage infection around $5 \%$ each.
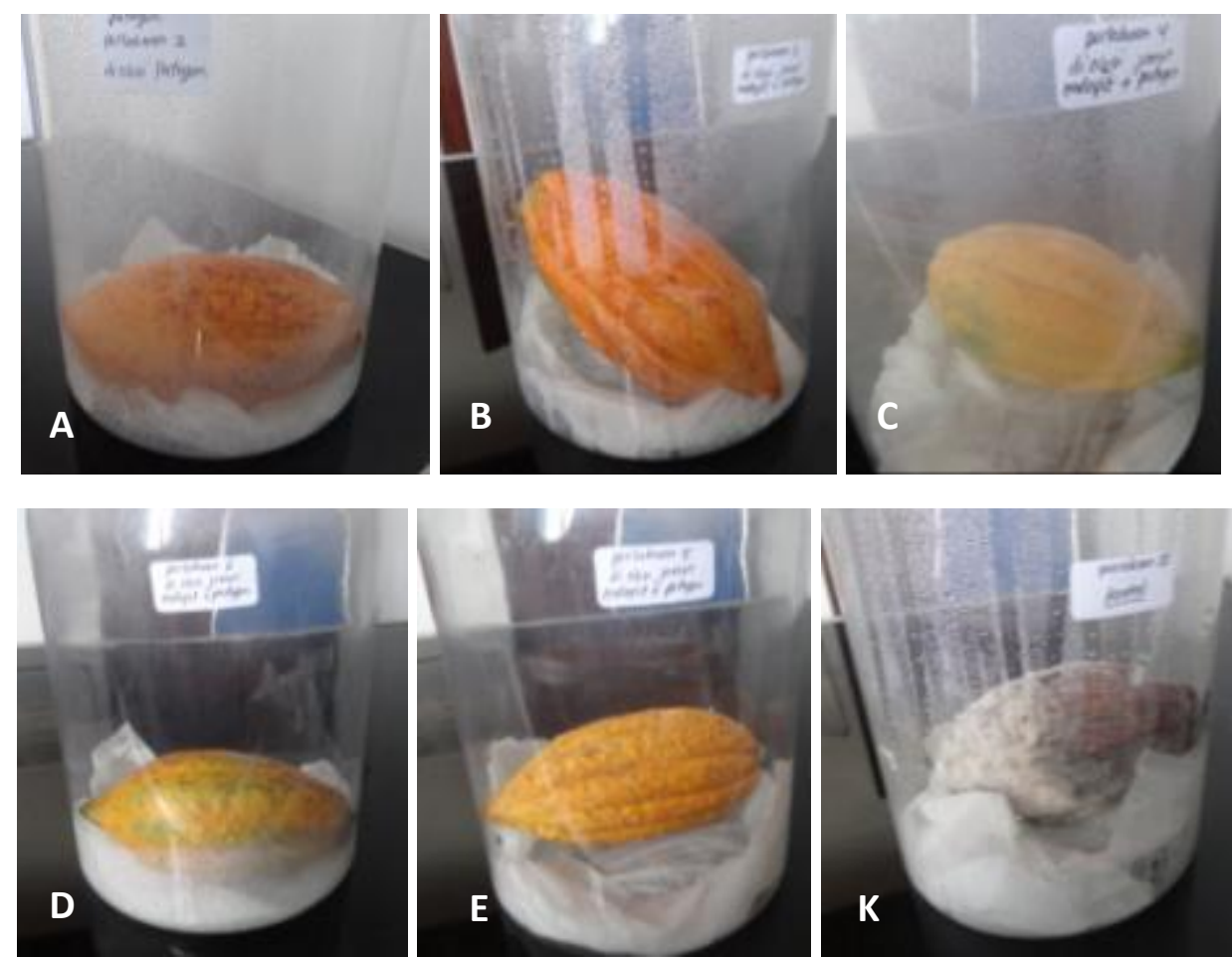

Fig. 3. The result of in vivo antagonisti: assay on fresh fruit (A) Aspegillus sp., (B) Aspergillus niger, (C) Aspergillus flavus, (D) Neurospora sp., (E) Trichoderma sp. and (K) Control 7 days after incubation

TABLE 3.

THE INFECTION PERCENTAGE OF P. PALMIVORA ON THE FRUIT IN EACH TREATMENT.

\begin{tabular}{clc}
\hline No. & \multicolumn{1}{c}{ Tretment } & Percentage of Infection \\
\hline 1 & Control & $100 \pm 0 \mathrm{a} * *$ \\
2. & Treatment with Aspergillus sp. & $10 \pm 0,2 \mathrm{~b}$ \\
3. & Treatment with Aspergillus niger & $5 \pm 0,1 \mathrm{~b}$ \\
4. & Treatment with Aspergillus flavus & $5 \pm 0,3 \mathrm{~b}$ \\
5. & Treatment with Neurosporas sp. & $5 \pm 0,2 \mathrm{~b}$ \\
6. & Treatment with Trichoderma sp. & $5 \pm 0,1 \mathrm{~b}$ \\
\hline \multicolumn{2}{c}{ ** Significant different at BNT $1 \%}$.
\end{tabular}

\section{CONCLUSION}

Endophytic fungi which have been found on the leaf, rod and fruit skin of healthy cocoa are 15 species, with prevalence of endophytic fungi from healthy leaf are Mecelia sterilia (sterile hifa) around 30\%, on the endophyte from healthy rod it's found mycelia sterilia, Neurospora spp. and Trichoderma spp. around 25\% of each. While at the endophyte originated from fruit skin, it's found Trichoderma spp. around 35\%. The in vitro antagonistic assay results of endophytic fungi to $P$. palmivora showed that at the endophyte from leaf its obtained Aspergilus spp. around $80 \pm 2 \%$, A. niger $90 \pm 2 \%$, A. flavus $100 \%$, and Trichoderma spp. around $90 \pm 1,5 \%$. On the endophyte from rod, it's obtained $95 \pm 2 \%$ of Neurospora spp. and $90 \pm 2 \%$ of Trichoderma spp. While endophyte from the fruit skin, its obtained $95 \pm 1,5 \%$ of Neurospora spp. and $80 \pm 2 \%$ of Trichoderma spp. The result of in vivo antagonistic assay showed that all of endophytic fungi (Aspergillus sp., A. niger, A. flavus, Neurospora sp., dan Trichoderma sp.) have a significant effect on inhibition the mycelium growth of $P$. palmivora. 


\section{ACKNOWLEDGMENT}

We acknowledge the rector of Udayana University, the head of the LPPM, The dean of Faculty of Agriculture, Udayana University, for all the support from the start until finishing of this research.

\section{REFERENCES}

[1] Semangun, H. 1991. Penyakit-Penyakit Penting Tanaman Perkebunan di Indonesia. Yogyakarta: Gadjah Mada University Press.

[2] USDA, 2012. Phytophthora palmivora Pests and Diseases of American Samoa. American Samoa Community College Community \& Natural Resources Coope-rative Research \& Extension 12:12.

[3] Purwantara, A., D. Manohara and J.S. Warokka. 2004. Phytophthora Diseases in Indonesia. In Diversity and Management of Phytophthora in Southeast Asia Edited by A. Drenth and D.I. Guest, ACIAR Monograph 114:70-75.

[4] Mejia L.C., E.I. Rojas, Z. Maynard, S.V. Bael, A.E. Arnold, P. Hebbar, G.J. Damuels, N. Robbins, and E.A. Herre. 2008. Endophytic fungi as biocontrol agents of Theobroma cacao pathogens. Biological Control 46:4-14.

[5] Samson, R.A., E.S. Hoekstra, and C.A.N. Van Oorschot. 1981. Introduction to Food-Borne Fungi. Centraalbureau Voor-Schimmelcultures. Institute of The Royal Netherlands. Academic of Arts and Sciences.

[6] Pitt, J.I. and A.D. Hocking. 1997. Fungi and Food Spoilage. 2nd Edition. London: Blackie Avademic and Professional.

[7] Barnett, H.L. and B.B. Hunter. 1998. Illustrated Genera of Imperfect Fungi. APS Press. Minnesota: The American Phytopathological Society.

[8] Indrawati. G., R.A. Samson, K. Van den TweelVermeulen, A. Oetari and I. Santoso. 1999. Pengenalan Kapang Tropik Umum. Yayasan Obor Indonesia. University of Indonsia Culture Collection Depok, Indonsia and Centraal bureau voor Schirmmelcultures, Baarn, The Netherlands.

[9] Dolar, F.S. 2001. Antagonistic effect of Aspergillus melleus Yukawa on soilborne pathogens of Chickpea, Tarim Bilimleri Dergisi 8(2):167-170.

[10] Mojica-Marin, V., H.A. Luna-Olvera, C.F. Sandoval-Coronado, B. Pereyra-Alférez, H. Lilia,
Morales-Ramos, E. Carlos, Hernández-Luna, and G.O. Alvarado-Gomez. 2008. Antago-nistic activity of selected strains of Bacillus thuringiensis against Rhizoctonia solani of chili pepper. African Journal of Biotechnology, 7 (9):1271-1276.

[11] Faeth, S.H. 2002. Are endophytic fungi defensive plant multualist? Oikos 98:25-36.

[12] Gazis, R. and P. Chaverri. 2009. Diversity of fungal endophytes in leaves and stems of wild rubber trees (Hevea brasiliensis) in Peru. Fungal Ecology 3:240254.

[13] Zhao, J., L. Zhou, J. Wang, T. Shan, L. Zhoung, X. Liu, and X. Gao. 2010. Endophytic fungi for producing bioactive compound originally from their host plants. In Current Research, Technology and Educa-tion Topics in Applied Microbiology and Microbial Biotechnology. A. Mendez-Villas (Ed.) Formatex pp.567- 576

[14] Amin, N., M. Salam, M. Junaid, Asman and M. S Baco. 2014. Isolation and identification of endophytic fungi from cacao plant resistant VSD M.05 and cacaomplant susceptible VSD M.01 in South Sulawesi, Indonesia. International Journal of Current Micorbiology and Applied Science. 3(2):459-467.

[15] Saithong, P., W. Panthavee, S. Stonsaovapak, and L. Congfa. 2010. Isolation and primary identification of endophytic fungi from Cephalotaxus manii trees. Maejo Int. J. Sci. Technol. 4(03): 446-453.

[16] Sharma, A.K., P. Sharma and R.B. Sharma. 2013. Characterization of anti-fungal property of seed coat leafchates of Jatropa curcas L. IJBAF 1(10):446451.

[17] Rubini, M.R., R.T. Silva-Ribeiro, A.W.V. Pemella, C.S. Maki, W.A. Araujo, D.R. dos Santos, and J.L. Azevedo. 2005. Diversity of endophytic fungal community of cacao (Theobroma cacao L.) and biological control of Crinipellis perniciosa, causal agents of witches broom disease. Int. J. Biol. Sci. $1: 24-33$

[18] Mpika, J., B.I. Kebe and F.K. N'Guessan. 2011. Isolation and Identification of Indigenous Microorganisms of Cocoa Farms in Côte d'Ivoire and Assessment of Their Antagonistic Effects VisÀ-Vis Phytophthora palmivora, the Causal Agent of the Black Pod Disease, Biodiversity Loss in a Changing Planet 303-318. 